\title{
Isca tóxica e disrupção sexual no controle da mosca-da-fruta sul-americana e da mariposa-oriental em pessegueiro
}

\author{
Wagner da Roza Härter(1), Anderson Dionei Grützmacher ${ }^{(1)}$, Dori Edson Nava(2), \\ Rafael da Silva Gonçalves ${ }^{(1)}$ e Marcos Botton ${ }^{(3)}$
}

\begin{abstract}
(1)Universidade Federal de Pelotas, Faculdade de Agronomia Eliseu Maciel, Departamento de Fitossanidade, Campus Universitário, s/nº, Caixa Postal 354, CEP 96010-900 Pelotas, RS. E-mail: wagnerharter@gmail.com, anderson.grutzmacher@pq.cnpq.br, rafaeldasilvagoncalves@gmail.com, (2)Embrapa Clima Temperado, Caixa Postal 403, CEP 96001-970 Pelotas, RS. E-mail: nava@cpact.embrapa.br ${ }^{(3)}$ Embrapa Uva e Vinho, Caixa Postal 130, CEP 95700-000 Bento Gonçalves, RS. E-mail: marcos@cnpuv.embrapa.br
\end{abstract}

Resumo - O objetivo deste trabalho foi avaliar o emprego simultâneo de isca tóxica e da técnica de disrupção sexual, com uso de feromônio sexual, para o controle de Anastrepha fraterculus e Grapholita molesta, em pomar comercial de pessegueiro. Foram utilizados três pomares de 0,5 ha, com os seguintes tratamentos: pomar 1, manejo com isca tóxica (Biofruit 3\% + Malathion $500 \mathrm{CE}$ a $200 \mathrm{~mL}$ por $100 \mathrm{~L}$ ), aplicada nas plantas da borda do pomar quando o nível de controle era atingido, e uso da disrupção sexual por meio da aplicação de feromônio (Splat Grafo) em 1.000 pontos por ha; pomar 2, manejo convencional, constituído por pulverizações com inseticidas de contato e ingestão de 2 a 3 vezes ao ano; pomar 3 , testemunha, sem controle. A população de adultos das duas espécies e o dano em ponteiros e frutos foram monitorados nas safras 2007/2008 e 2008/2009. O uso simultâneo da isca tóxica e da técnica de disrupção sexual reduziu em mais de $90 \%$ a captura de adultos de A. fraterculus e G. molesta. Nas duas safras, os danos reduziram de $62-85 \%$ em ponteiros, e de $98-99 \%$ nos frutos, em comparação à testemunha sem controle.

Termos para indexação: Anastrepha fraterculus, Grapholita molesta, Prunus persica, feromônio sexual, manejo de pragas, produção integrada de pêssego.

\section{Toxic bait and mating disruption to control the American fruit fly and the oriental fruit moth on peach orchards}

\begin{abstract}
The objective of this work was to evaluate the simultaneous use of toxic bait and mating disruption technique using sexual pheromone for Anastrepha fraterculus and Grapholita molesta control, in commercial peach orchards. Three 0.5-ha orchards were used, with the following treatments: orchad 1, toxic bait (Biofruit $3 \%$ + Malathion $500 \mathrm{CE}, 200 \mathrm{~mL}$ in $100 \mathrm{~L}$ ) and mating disruption using sexual pheromone (Splat Grafo) in 1,000 points ha $^{-1}$; orchad 2 , conventional management, using contact insecticides 2 to 3 times a year; orchad 3 , no pest control. Adult populations of both species, and sprout and fruit damages were monitored during the 2007/2008 and 2008/2009 crop seasons. Simultaneous use of toxic bait and mating disruption technique decreased the captures of A. fraterculus and G. molesta in more than $90 \%$. In the two crop seasons, the damages on sprouts decreased $62-85 \%$, and $98-99 \%$ on fruit, compared to the untreated orchard.
\end{abstract}

Index terms: Anastrepha fraterculus, Grapholita molesta, Prunus persica, sexual pheromone, pest management, peache integrated production.

\section{Introdução}

O Rio Grande do Sul é o maior produtor de pêssegos do Brasil, sendo responsável por $50 \%$ da produção nacional (Instituto FNP, 2008). Um dos fatores limitantes à produtividade da cultura é a ocorrência de insetos-praga, com destaque para a mosca-da-fruta sul-americana Anastrepha fraterculus (Wiedemann, 1830) (Diptera: Tephritidae) e a mariposa-oriental Grapholita molesta (Busck, 1916) (Lepidoptera:
Tortricidae) (Botton et al., 2005; Monteiro et al., 2008). As perdas ocasionadas por essas pragas, caso não estejam controladas, chegam a $100 \%$ da produção (Salles, 1998).

A importância de $A$. fraterculus deve-se aos danos diretos causados pelas perfurações do ovipositor e pelo desenvolvimento das larvas no interior dos frutos, inviabilizando-os para o consumo (Salles, 1999), com prejuízo econômico. No caso de G. molesta, os danos 
são ocasionados pela alimentação das lagartas nas brotações e nos frutos (Salles, 2001). Os prejuízos são maiores quando esse inseto, ao se alimentar, favorece a entrada de doenças, como é o caso da podridão-parda do pessegueiro causada pelo fungo Monilinia fructicola (Botton et al., 2001). Quando ataca ponteiros de plantas novas, constitui-se em grave problema em viveiros e em pomares recém-implantados (Fachinello et al., 1996).

Para o controle de G. molesta e A. fraterculus, o sistema de manejo utilizado pelos produtores tem sido a pulverizacão de inseticidas organofosforados e piretroides, em área total, a cada 10 a 15 dias, seguindo um calendário predefinido (Arioli et al., 2004). Este manejo, embora eficaz quando se considera a redução nas perdas de produção, está se tornando inviável, em razão da crescente exigência dos consumidores por frutas de melhor qualidade, obtidas em sistemas de produção que protejam o ambiente e a saúde dos trabalhadores e consumidores (Normas de produção integrada de pêsssego, 2001; Fachinello et al., 2009).

Outra consequência da aplicação indiscriminada de inseticidas no controle da mosca-da-fruta e da grafolita é o aparecimento de pragas secundárias (Botton et al., 2005). Desta forma, o estabelecimento de um sistema de manejo para as duas principais pragas do pessegueiro torna-se fundamental para a manutenção destas populações em equilíbrio com as dos inimigos naturais.

Duas alternativas consideradas sustentáveis mostram-se promissoras para o manejo de G. molesta e de $A$. fraterculus na cultura do pessegueiro. Para G. molesta, o emprego da técnica da disrupção sexual é considerado promissor (Botton et al., 2005). Atualmente, dois liberadores de feromônio sexual estão disponíveis no mercado brasileiro (Monteiro et al., 2008; Pastori et al., 2008). No caso de $A$. fraterculus, iscas tóxicas tradicionalmente utilizadas em citros (Raga, 2005) e macieira (Kovaleski \& Ribeiro, 2003) são alternativas que devem ser avaliadas.

O objetivo deste trabalho foi avaliar o emprego simultâneo de isca tóxica para o controle de $A$. fraterculus e da técnica de disrupção sexual, utilizando liberadores de feromônio sexual, para o controle de G. molesta, em pomar comercial de pessegueiro.

\section{Material e Métodos}

O experimento para avaliar o uso de isca tóxica e de feromônio sexual sintético no controle de $A$. fraterculus e G. molesta, respectivamente, na cultura do pessegueiro, foi conduzido nas safras 2007/2008 e 2008/2009, em pomares comerciais da cultivar Esmeralda, localizados na Colônia Vila Nova, em Pelotas, RS. Os pomares foram implantados em 2003, no espaçamento de 5x2,5 m, selecionados em função da uniformidade das plantas, separados em três áreas de aproximadamente 0,5 ha cada, distantes entre si $500 \mathrm{~m}$.

Cada pomar recebeu um tipo de manejo de A. fraterculus e G. molesta. No pomar 1 (31'33'00"S, $52^{\circ} 29^{\prime} 12^{\prime \prime} \mathrm{W}$ ), realizou-se o manejo com isca tóxica e emprego da técnica de disrupção sexual com feromônio sexual sintético. No pomar $2\left(31^{\circ} 32^{\prime} 15^{\prime \prime} \mathrm{S}\right.$, e $\left.52^{\circ} 29^{\prime} 46^{\prime \prime} \mathrm{W}\right)$, foi realizado o manejo convencional das pragas conforme decisão do produtor, sendo utilizadas somente pulverizações de inseticidas de contato e ingestão. O pomar $3\left(31^{\circ} 32^{\prime} 54^{\prime \prime} \mathrm{S}, 52^{\circ} 29^{\prime} 25^{\prime \prime} \mathrm{W}\right)$ foi utilizado como testemunha, sem controle das pragas.

A isca tóxica, formulada com proteína hidrolisada, constituída por Biofruit a 3\% + malationa (Malathion $500 \mathrm{CE}, 200 \mathrm{~mL}$ i.a. por $100 \mathrm{~L}$ ), foi aplicada somente nas plantas localizadas na borda do pomar. A aplicação foi realizada levando-se em consideração o nível de controle preconizado para a cultura no sistema de produção integrada (Normas de produção integrada de pêssego, 2001). As aplicações foram realizadas com um pulverizador atomizador Jacto, com capacidade para $600 \mathrm{~L}$, equipado com bico leque, aplicando-se um volume de $80 \mathrm{~L} \mathrm{ha}^{-1}$, utilizando somente os bicos laterais, formando uma faixa de $1 \mathrm{~m}$ de largura em altura mediana da planta, em 10/11, 22/11 e 2/12/2007, e em 26/10, 2/11, 12/11 e 22/11/2008.

O feromônio sexual sintético Splat Grafo (Isca Tecnologias Ltda, Ijuí, Brasil), constituído por acetato de (E)-8-dodecenila, acetato de (Z)-8-dodecenila, Z-8-dodecenol, (4,4\%); (RS)-alpha-cyano-3-Phenoxybenzyl (1RS, 3RS, 1RS, 3SR)-)- 3-(2,2-dichlorovinyl)-2,2dimethylcyclopropanecarboxylate), foi utilizado na dose de $1 \mathrm{~kg} \mathrm{ha}^{-1}$, em 1.000 pontos de aplicação, a uma altura de $1,7 \mathrm{~m}$, em locais protegidos do sol. A aplicação foi realizada em 19/10/2007 e 6/10/2008.

O manejo convencional, na safra 2007/2008, foi realizado com duas aplicações do inseticida dimetoato na dose $40 \mathrm{~mL}$ i.a. por $100 \mathrm{~L}$ em $20 / 11$ e 30/11/2007. Na safra 2008/2009 foram realizadas duas aplicações de dimetoato na dose $40 \mathrm{~mL}$ i.a. por $100 \mathrm{~L}$ em $27 / 10$ e 23/11/2008, 
intercaladas por uma aplicação do inseticida Malathion $500 \mathrm{CE}$, na dose $200 \mathrm{~mL}$ i.a. por $100 \mathrm{~L}$, em 7/11/2008.

Nos três pomares, o monitoramento das populações de A. fraterculus e de G. molesta foi realizado ao longo das safras, utilizando-se quatro armadilhas McPhail contendo proteína hidrolisada (Bioanastrepha a 5\%) como isca para A. fraterculus, e quatro armadilhas Delta, contendo feromônio sexual (Iscalure Grafolita) para a G. molesta. Cada uma das armadilhas foi disposta em um dos quatro quadrantes do pomar, distanciada cerca de $50 \mathrm{~m}$ uma da outra. A avaliação do número de insetos capturados por armadilha foi realizada semanalmente, quando o atrativo para A. fraterculus era reposto. Para G. molesta, o atrativo foi reposto a cada quatro semanas.

O monitoramento de $A$. fraterculus foi realizado no período de $9 / 10$ a 28/12/2007 e de 6/10 a 29/12/2008, enquanto o de G. molesta foi realizado de 31/10/2007 a 21/03/2008 e de 6/10/2008 a 27/3/2009.

O dano causado por G. molesta nos ponteiros foi monitorado periodicamente em 1.000 ponteiros, observados em 10 pontos do pomar. Cada ponto foi considerado uma repetição, no total de 10 repetições de 100 ponteiros cada uma. Para $A$. fraterculus, no momento da colheita (12/12/2007 e 8/12/2008), foi registrado o dano causado pelo inseto nos frutos, avaliando-se 200 frutos, divididos em 10 repetições de 20 frutos cada uma. Nesta avaliação, o pomar foi dividido em 10 subáreas, descartando-se as plantas localizadas a menos de $3 \mathrm{~m}$ da borda. Os frutos foram colhidos e acondicionados em sacos de plástico, levados ao laboratório e dispostos em copos $(500 \mathrm{~mL})$ contendo vermiculita no fundo, de modo a absorver o excesso de umidade e, na abertura superior, fechados com um tecido voile. Após 20 dias, os copos foram abertos para o registro da presença de pupas. No mesmo dia em que os frutos foram colhidos para determinar a incidência de $A$. fraterculus, foram avaliados no campo 1.000 frutos para estimar os danos causados por G. molesta, dividindo-se a amostragem em 10 repetições de 100 frutos cada uma.

$\mathrm{O}$ experimento foi conduzido em delineamento inteiramente casualizado e cada armadilha instalada no pomar foi considerada uma repetição. Os dados foram submetidos à análise de variância não-paramétrica, utilizando o teste de Kruskal-Wallis. Os tratamentos foram analisados pelo teste de comparações múltiplas de StudentNewman-Keuls, a 5\% de probabilidade, utilizando o programa BioEstat 5.0 (Ayres et al., 2007). A percentagem de redução de danos foi calculada pela fórmula de Abbott (1925).

\section{Resultados e Discussão}

$\mathrm{Na}$ safra 2007/2008, foi capturado 0,5 adulto de $A$. fraterculus por armadilha por dia, na testemunha, em 19/10/2007 (Figura 1). Em 20/11/2007, foi observado o segundo pico populacional na testemunha com três moscas por armadilha por dia, quando os frutos estavam na fase de inchamento, susceptíveis ao ataque do inseto (Salles, 1994). A população de A. fraterculus voltou a aumentar no período próximo à colheita, quando foram registradas 12 moscas por armadilha por dia. Os tratamentos isca tóxica e manejo convencional reduziram a captura de adultos nas áreas tratadas em comparação à testemunha. Durante o pico populacional máximo na testemunha (12 moscas por armadilha por dia), a isca tóxica e o manejo convencional reduziram as capturas em 94 e 91\%, respectivamente.

Na safra 2008/2009, a população de $A$. fraterculus na testemunha apresentou pico populacional antecipado, com 0,86 e 4 moscas por armadilha por dia em 13/10 e 27/10/2008, respectivamente (Figura 1), com pico máximo de 55 moscas por armadilha por dia, em $3 / 11 / 2008$. Da mesma forma que o observado na safra $2007 / 2008$, os pomares que receberam os tratamentos isca tóxica e manejo convencional reduziram a população em 99,5 e 99\%, respectivamente, em relação à testemunha. Esse resultado confirma a eficácia da isca tóxica no controle da infestação da praga. A população de A. fraterculus na área testemunha, na safra 2008/2009, foi superior à da safra de 2007/2008, apresentando um total de 1.248 e 242 moscas, respectivamente.

Na safra 2007/2008, nos tratamentos isca tóxica e manejo convencional, não foram observados danos aos frutos causados por $A$. fraterculus. Esses tratamentos não diferiram significativamente entre si, mas diferiram da testemunha, que apresentou 7,0 $0,3 \%$ de frutos danificados. Na safra 2008/2009, o mesmo comportamento foi observado, porém com $27,5 \pm 0,5 \%$ de frutos atacados na testemunha. Não foram localizados relatos na literatura sobre o efeito de iscas tóxicas no controle da $A$. fraterculus na fruticultura de clima temperado, no Brasil. Tibola et al., 2005 menciona que as iscas tóxicas foram empregadas no controle da mosca-da-fruta sul-americana em pessegueiro 
cultivado no sistema de produção integrada, sendo uma estratégia importante para o manejo da praga na cultura.

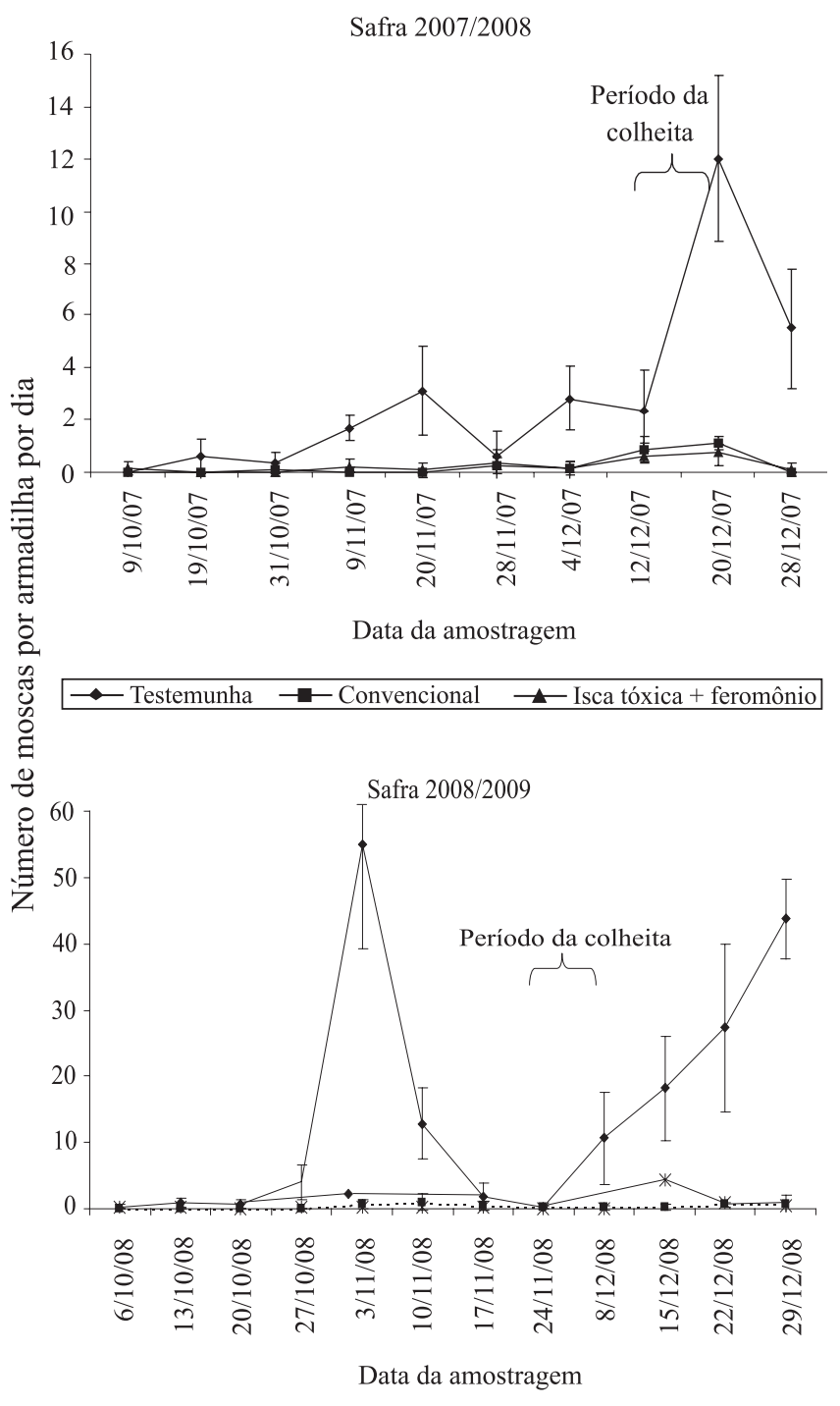

Figura 1. Flutuação populacional de adultos de Anastrepha fraterculus capturados por dia em armadilhas McPhail contendo iscas com proteína hidrolisada (Bioanastrepha 5\%), em pomares de pessegueiro da cultivar Esmeralda, nas safras de 2007/2008 e 2008/2009. Testemunha, sem controle; convencional, pulverizações com inseticidas de contato e ingestão; isca tóxica (Biofruit a 3\% + Malathion $500 \mathrm{CE}, 200 \mathrm{~mL}$ i.a. por 100L)+feromônio(SplatGrafo). Datas deaplicaçãodos produtos: isca tóxica, em 10/11/2007, 22/11/2007, 2/12/2007, 26/10/2008, 2/11/2008, 12/11/2008 e 22/11/2008; feromônio sexual, em 19/10/2007 e 6/10/2008; dimetoato no manejo convencional, em 20/11/2007, 30/11/2007, 27/10/2008 e 23/11/2008; malationa no manejo convencional, em 10/11/2008.
Com base nos dois anos de observação, verificouse que o uso de isca tóxica foi eficaz no controle de $A$. fraterculus na cultura do pessegueiro sem a necessidade de se utilizar inseticidas. Esta prática, tradicionalmente empregada em pomares de citros (Raga, 2005) e macieira (Kovaleski \& Ribeiro, 2003), poderia ser implantada para o manejo da espécie também em pomares de pessegueiro. Desse modo, propiciaria risco reduzido em razão da menor presença de resíduos tóxicos nos frutos, maior preservação dos inimigos naturais nos pomares, diminuição do ressurgimento de pragas secundárias e redução no volume de inseticidas aplicados nos pomares, quando comparado com as pulverizações realizadas em área total. Ao se comparar com as pulverizações no manejo convencional, a isca tóxica reduziu o uso de inseticidas de 400 para $240 \mathrm{~g} \mathrm{ha}^{-1}$ de i.a. na safra 2007/2008 e de 900 para $320 \mathrm{~g} \mathrm{ha}^{-1}$ de i.a. na safra 2008/2009. Ademais, o principal inseticida empregado em pulverizações (dimetoato) na região não é autorizado para uso na cultura (Agrofit, 2009), o que gera problemas de inconformidades em relação a análises de resíduos. No entanto, a utilização de iscas tóxicas para o controle de $A$. fraterculus não é uma prática adotada pelos produtores de pêssego, pois requer mudança no sistema de manejo das pragas, com substituição das aplicações por calendário pela realização de monitoramento. Outro fator que dificulta a aceitação do uso das iscas tóxicas é o baixo custo dos inseticidas fosforados e a facilidade de sua aplicação conjunta com fungicidas.

Para G. molesta, na safra 2007/2008, a captura de adultos ocorreu a partir da instalação das armadilhas nos pomares (Figura 2). A população de $G$. molesta nos tratamentos manejo convencional e testemunha foi crescente ao longo das avaliações, com pico populacional em $15 / 1 / 2008$, quando foram capturados 80 e 55 insetos por armadilha por semana, respectivamente. No entanto, esse nível populacional foi observado após a colheita dos frutos, quando o dano ocorre somente nos ponteiros, o que não é considerado problema em plantas adultas (Fachinello et al., 1996). Entretanto, isto pode contribuir para maior infestação na safra seguinte, já que geralmente os produtores não fazem tratamento de pós-colheita para o controle dessa praga. Na área tratada com feromônio sexual, nesta data, foram capturados 2,75 insetos por armadilha por semana. A redução nas capturas observada após a colheita do pessegueiro com uso da técnica de disrupção 
sexual pode auxiliar na redução das infestações nas safras seguintes, conforme observado em macieira (Pastori et al., 2008). De forma geral, na área tratada com feromônio sexual a captura de G. molesta foi no mínimo 95\% menor, quando comparada à testemunha.

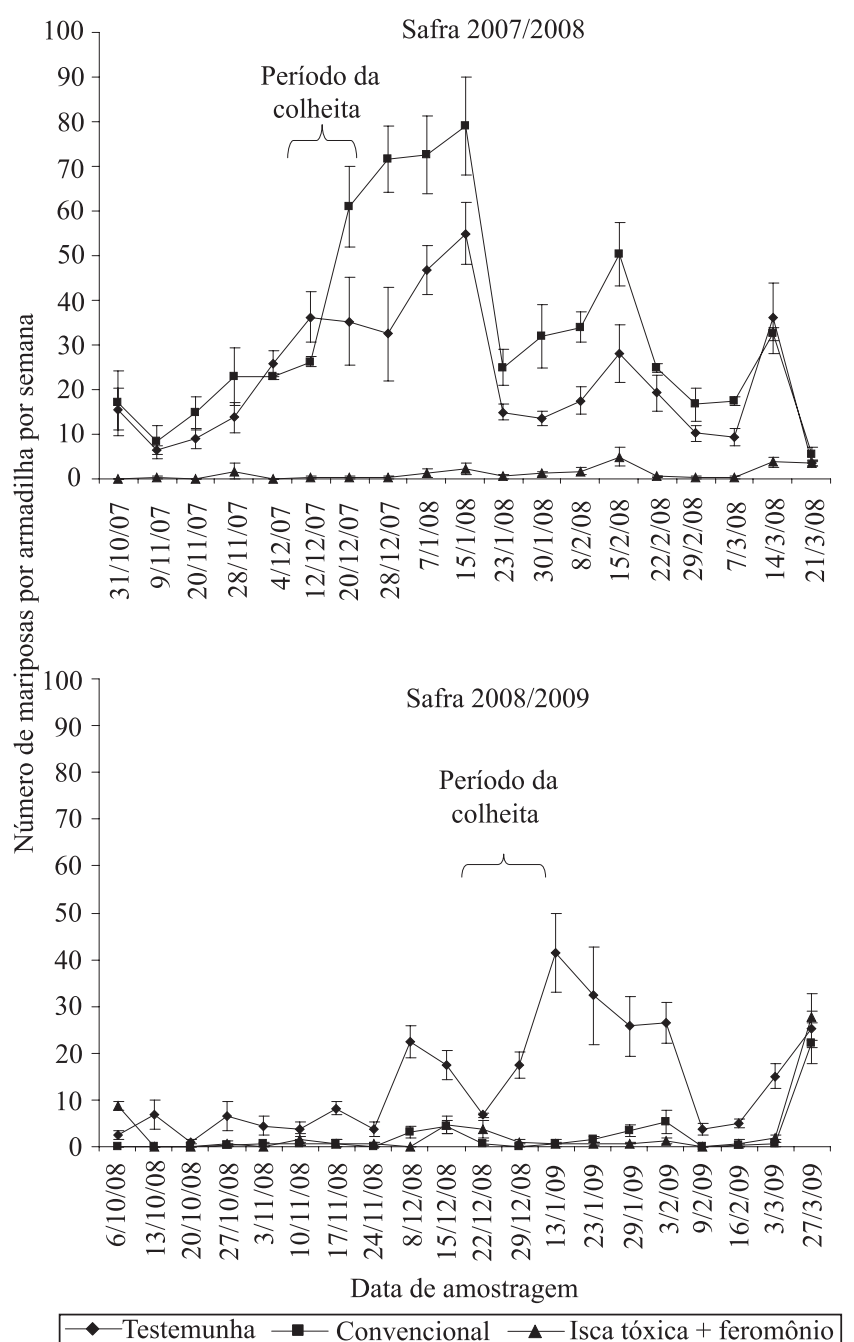

Figura 2. Flutuação populacional de adultos da Grapholita molesta, capturados em armadilhas contendo iscas com feromônio sexual sintético (Iscalure Grafolita), em pomares de pessegueiro da cultivar Esmeralda nas safras 2007/2008 e 2008/2009. Testemunha, sem controle; convencional, pulverizações com inseticidas de contato e ingestão; isca tóxica, (Biofruit a 3\% + Malathion $500 \mathrm{CE}, 200 \mathrm{~mL}$ i.a. por 100 L) + feromônio (Splat Grafo). Datas de aplicação dos produtos: isca tóxica, em 10/11/2007,22/11/2007, 2/12/2007, 26/10/2008, 2/11/2008, 12/11/2008 e 22/11/2008; feromônio sexual, em 19/10/2007 e 6/10/2008; dimetoato no manejo convencional, em 20/11/2007 e 30/11/2007, 27/10/2008 e 23/11/2008; malationa, no manejo convencional, em $10 / 11 / 2008$.
Na safra 2008/2009, a população de G. molesta foi menor (Figura 2). Em 13/10/2008, uma semana após a instalação dos emissores de feromônio sexual, a população de adultos na testemunha foi reduzida em $100 \%$, o que demonstra a redução nos acasalamentos na área tratada. $\mathrm{O}$ maior pico populacional foi registrado em 13/1/2009, com 41,5 insetos capturados por armadilha na testemunha, enquanto no pomar onde se utilizou feromônio sexual, bem como no de manejo convencional, o número de insetos capturados foi de 0,75 , com redução das capturas em $98 \%$ em ambos tratamentos.

$\mathrm{Na}$ avaliação de danos em ponteiros na safra 2007/2008, o único pomar que não apresentou danos significativos de G. molesta foi o tratado com ferômonio sexual, que diferiu significativamente do manejo convencional e da testemunha na maioria das avaliações (Figura 3). No manejo convencional e na testemunha, o pico de dano nos ponteiros ocorreu na metade do mês de janeiro de 2008, com índices de 45 e $55 \%$, respectivamente, enquanto na área com feromônio esse índice foi de apenas 9\%. Com base na data de aplicação e na redução significativa de capturas nas armadilhas, verificou-se que o produto permaneceu ativo por, no mínimo, 21 semanas, resultado similar aos encontrados para G. molesta em macieira (Pastori et al., 2008).

$\mathrm{Na}$ safra 2008/2009, a captura de adultos nas armadilhas de feromônio e o dano em ponteiros foram menores que na safra 2007/2008. Nas duas primeiras avaliações, os tratamentos manejo convencional e com feromônio diferiram significativamente da testemunha. Na terceira avaliação (15/12/2008), somente no manejo convencional houve redução na ocorrência de danos causados por G. molesta, e no tratamento feromônio, houve incremento no nível de ponteiros danificados. $\mathrm{Na}$ quarta avaliação (15/1/2009), os tratamentos manejo convecional e feromônio diferiram novamente da testemunha, com redução dos danos causados por G. molesta. Devido à baixa infestação observada na safra 2008/2009, não foi possível determinar o exato momento da perda de atividade do feromônio sexual, porém foi observada a sua eficiência por até 15 semanas.

Quanto ao dano causado por G. molesta nos frutos na safra 2007/2008, os tratamentos manejo convencional e feromônio não diferiram entre si e apresentaram $0,1 \%$ de frutos atacados, porém diferiram significativamente 
da testemunha (1,3\%). Na safra 2008/2009, novamente os tratamentos manejo convencional e feromônio apresentaram 0,8 e $0,2 \%$ de danos, respectivamente, e diferiram da testemunha que apresentou dano de $2,3 \%$.

O tramento com feromônio sexual sintético reduziu a captura de machos de G. molesta nas armadilhas e o dano nos ponteiros e frutos. Esses resultados indicam que existe potencial de utilização dessa tecnologia também na cultura do pêssego, a exemplo do que ocorre

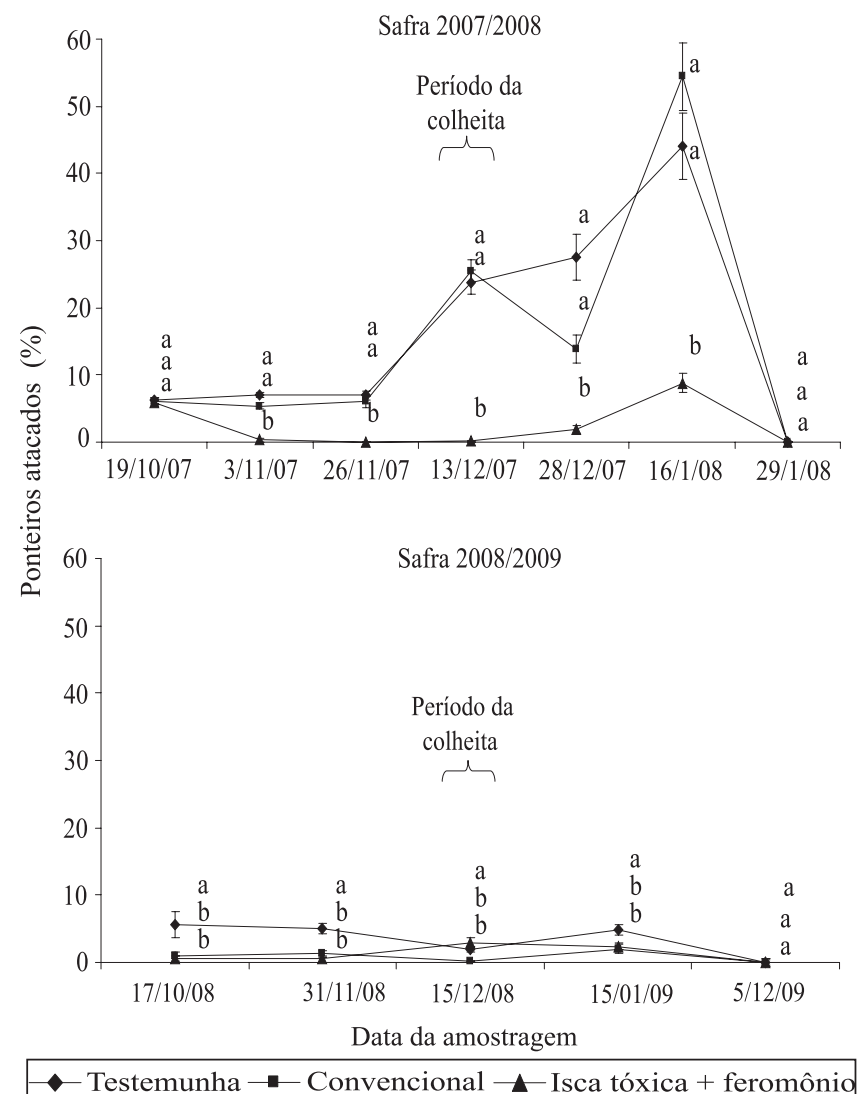

Figura 3. Percentagem de ponteiros atacados por Grapholita molesta em pomares de pessegueiro da cultivar Esmeralda nas safras 2007/2008 e 2008/2009. Testemunha, sem controle; convencional, pulverizações de inseticidas de contato e ingestão; isca tóxica (Biofruit a 3\% + Malathion $500 \mathrm{CE}$, $200 \mathrm{~mL}$ i.a. por 100 L) + feromônio (Splat Grafo). Médias seguidas de letras iguais não diferem entre si, pelo teste de Student-Newman-Keuls, a 5\% de probabilidade. Datas de aplicação dos produtos: isca tóxica, em 10/11/2007, 22/11/2007, 2/12/2007, 26/10/2008, 2/11/2008, 12/11/2008 e 22/11/2008; feromônio sexual, em 19/10/2007 e 6/10/2008; dimetoato no manejo convencional, em 20/11/2007, 30/11/2007, 27/10/2008 e 23/11/2008; malationa no manejo convencional, em 10/11/2008. na cultura da maçã (Monteiro et al., 2008; Pastori et al., 2008).

Ao se considerar os danos em frutos causados por G. molesta e A. fraterculus na safra 2007/2008, de $8,3 \%$ na testemunha, $0,1 \%$ na isca tóxica + feromônio sexual e $0,1 \%$ no manejo convencional e, na safra $2008 / 2009$, de $29,8 \%$ na testemunha, $0,2 \%$ na isca tóxica + feromônio sexual e $0,8 \%$ no convencional, chega-se à conclusão de que o uso das duas tecnologias de forma associada apresenta-se como uma estratégia importante para controlar as duas principais pragas na cultura do pêssego.

\section{Conclusão}

O uso simultâneo da isca tóxica e da técnica de disrupção sexual é eficaz para o controle de A. fraterculus e $G$. molesta, na cultura do pêssego.

\section{Agradecimentos}

À FAPERGS, pelo financiamento de parte do trabalho.

\section{Referências}

ABBOTT, W.S. A method of computing the effectiveness of an insecticide. Journal of Economic Entomology, v.18, p.265-267, 1925.

AGROFIT. Sistema de agrotóxicos fitossanitários. Disponível em: <http://www.agrofit.com.br>. Acesso em: 26 jul. 2009.

ARIOLI, C.J.; BOTTON, M.; CARVALHO, G.A. Controle químico de Grapholita molesta (Busck) (Lepidoptera: Tortricidae) na cultura do pessegueiro. Ciência Rural, v.34, p.1695-1700, 2004.

AYRES, M.; AYRES JÚNIOR, M.; AYRES, D.L.; SANTOS, A. de A.S. dos. BioEstat 5.0: aplicações estatísticas nas áreas das ciências biológicas e médicas. Belém: Sociedade Civil Mamirauá, 2007. 364p.

BOTTON, M.; ARIOLI, C.J.; COLLETTA, V.D. Monitoramento da mariposa oriental Grapholita molesta (Busck, 1916) na cultura do pessegueiro. Bento Gonçalves: Embrapa Uva e Vinho, 2001. 4p. (Embrapa Uva e Vinho. Comunicado técnico, 38).

BOTTON, M.; KULCHESKI, F.; DALlA COLlETTA, V.; ARIOLI, C.J.; PASTORI, P.L. Avaliação do uso do feromônio de confundimento no controle de Grapholita molesta (Lepidoptera: Tortricidae) em pomares de pessegueiro. Idésia, v.23, p.43-50, 2005.

FACHINELLO, J.C.; MIO, L.L.M. de; RANGEL, A. Produção integrada de pêssego. In: ZAMBOLIM, L.; NASSER, L.C.B.; ANDRIGUETO, J.R.; TEIXEIRA, J.M.A.; KOSOSKI, A.R.; 
FACHINELLO, J.C. (Org.). Produção integrada no Brasil: agropecuária sustentável, alimentos seguros. Brasília: Ministério da Agricultura, Pecuária e Abastecimento, 2009. p.781-809.

FACHINELLO, J.C.; NACHTIGAL, J.C.; KERSTEN, E. Fruticultura: fundamentos e práticas. Pelotas: UFPel, 1996. 311p.

INSTITUTO FNP. Agrianual 2008. São Paulo: Instituto FNP, 2008. p.493-502.

KOVALESKI, A.; RIBEIRO, L.G. Manejo de pragas na produção integrada de maçã. In: PROTAS, J.F. da. S.; VALDEBENITO SANHUEZA, R.M. Produção integrada de frutas: o caso da maçã no Brasil. Bento Gonçalves: Embrapa Uva e Vinho, 2003. p.61-68.

MONTEIRO, L.B.; SOUZA, A. de; BELLI, L. Confusão sexual para o controle de Grapholita molesta (Lepidoptera: Tortricidae), em pomares de macieira, em Fraiburgo (SC), Brasil. Bragantia, v.67, p.191-196, 2008.

NORMAS de produção integrada de pêssego (PIP). Pelotas: UFPel, 2001. 52p.

PASTORI, P.L.; ARIOLI, C.J.; BOTTON, M.; MONTEIRO, L.B.; MAFRA NETO, A. Avaliação da técnica de disrupção sexual utilizando emissores SPLAT visando ao controle de Bonagota salubricola (Meyrick) e Grapholita molesta (Busck) (Lepidoptera: Tortricidae) na pré-colheita de maçãs da cultivar 'Fuji'. BioAssay, v.3, p.1-8, 2008.

RAGA, A. Incidência, monitoramento e controle de moscas-das-frutas na Citricultura Paulista. Laranja, v.26, p.307-322, 2005.

SALLES, L.A.B. de. A Mariposa-oriental, Grapholita molesta (Lepidoptera: Tortricidae). In: VILELA, E.F.; ZUCCHI, R.A.; CANTOR, F. (Ed.). Histórico e impacto das pragas introduzidas no Brasil. Ribeirão Preto: Holos, 2001. p.42-45.

SALLES, L.A.B. de. Ocorrência precoce da mosca das frutas em ameixas. Ciência Rural, v.29, p.349-350, 1999.

SALLES, L.A.B. de. Períodos de ataque e de controle da mosca das frutas em pessegueiro. HortiSul, v.3, p.47-51, 1994.

SALLES, L.A.B. de. Principais pragas e seu controle. In: MEDEIROS, C.A.B.; RASEIRA, M. do C. (Ed.). A cultura do pessegueiro. Brasília: Embrapa-SPI; Pelotas: Embrapa-CPACT, 1998. p.205-239.

TIBOLA, C.S.; FACHINELLO, J.C.; GRÜTZMACHER, A.D.; PICOLOTTO, L.; KRÜGER, L. Manejo de pragas e doenças na produção integrada e convencional de pêssegos. Revista Brasileira de Fruticultura, v.27, p.215-218, 2005.

Recebido em 9 de setembro de 2009 e aprovado em 29 de janeiro de 2010 